sala preta

ppgac vol. 11, n. 1, dez 2011, p. 186-192

Dossiê Espetáculo

\section{Ensaio de imagens}

Cláudio Etges
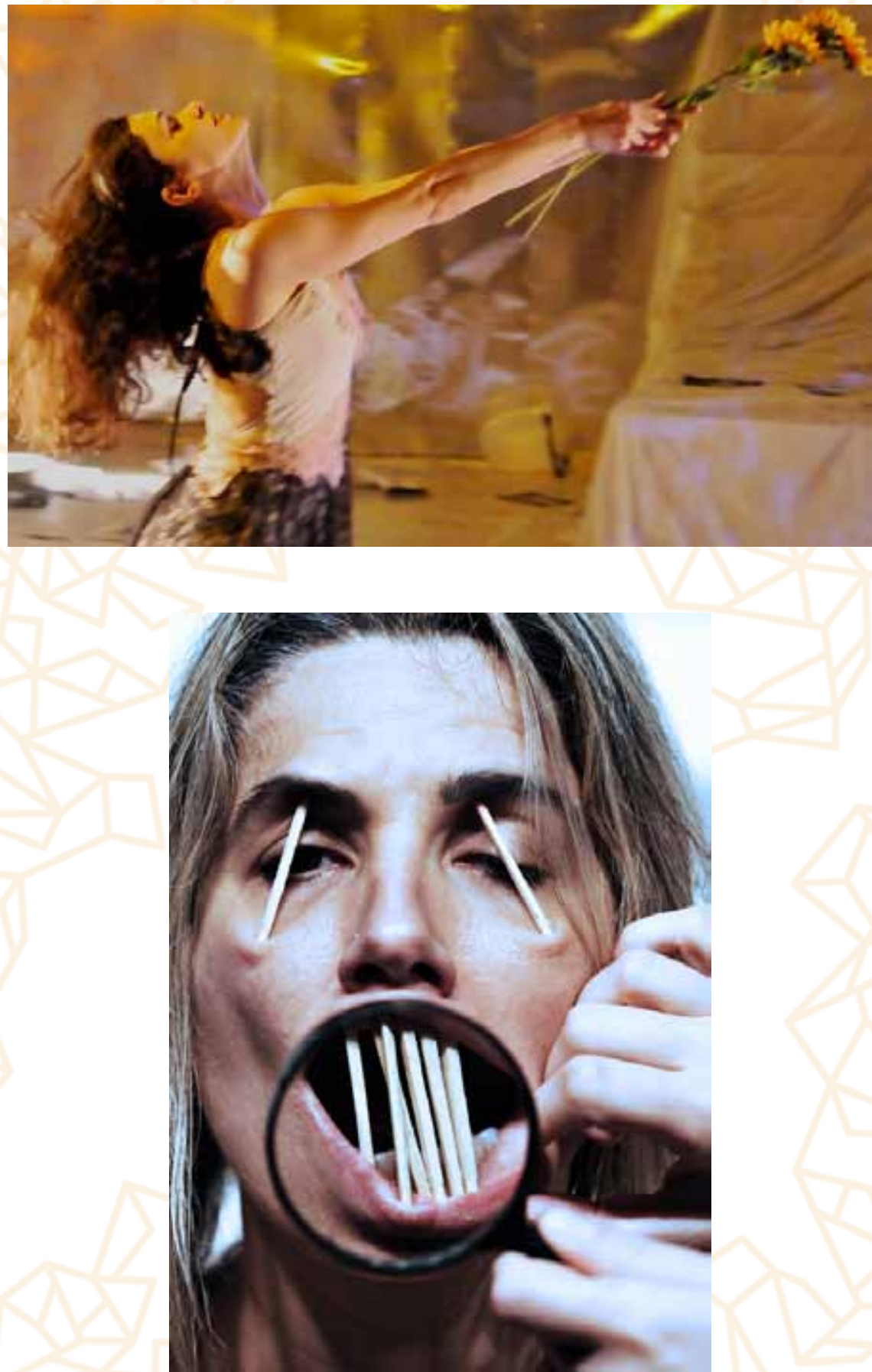

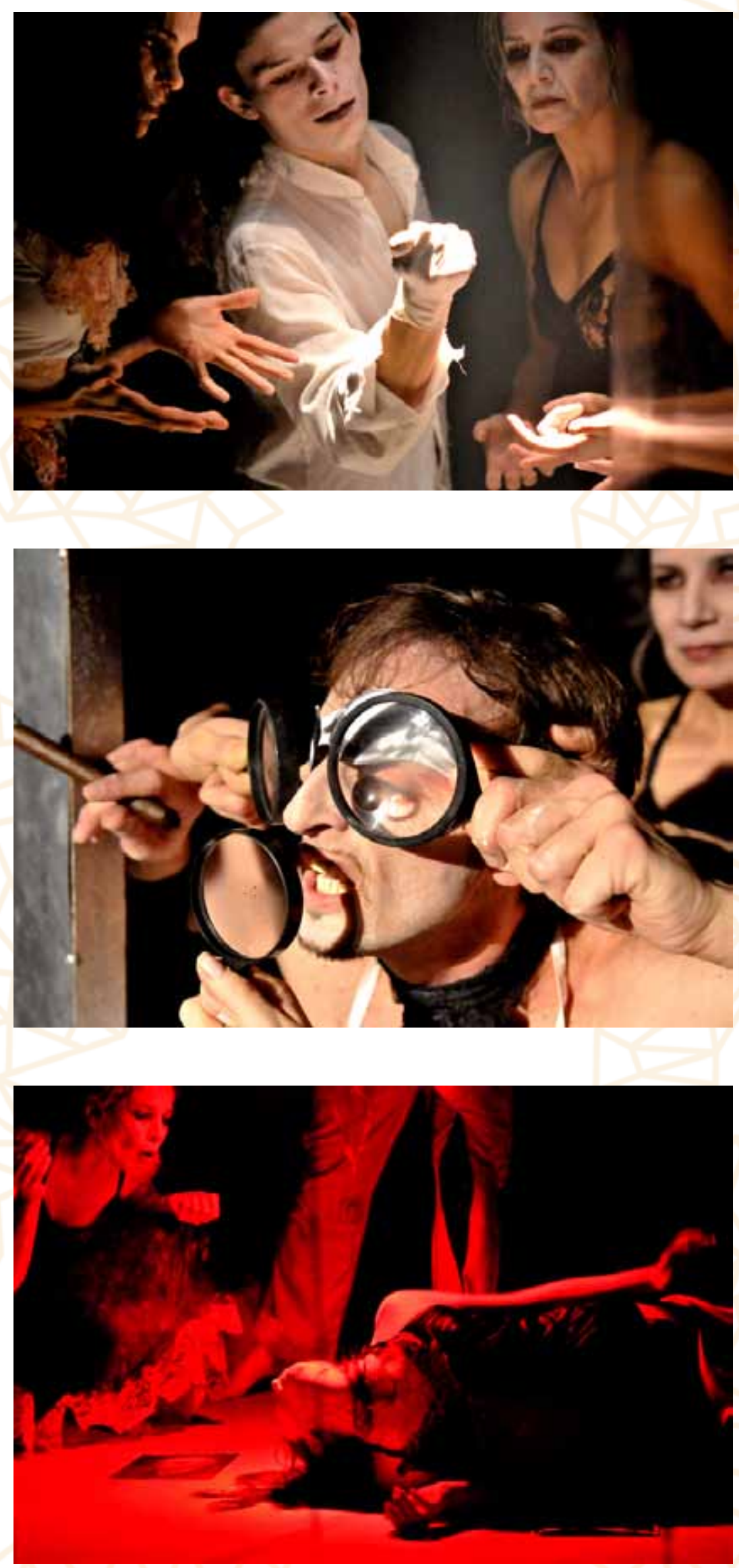

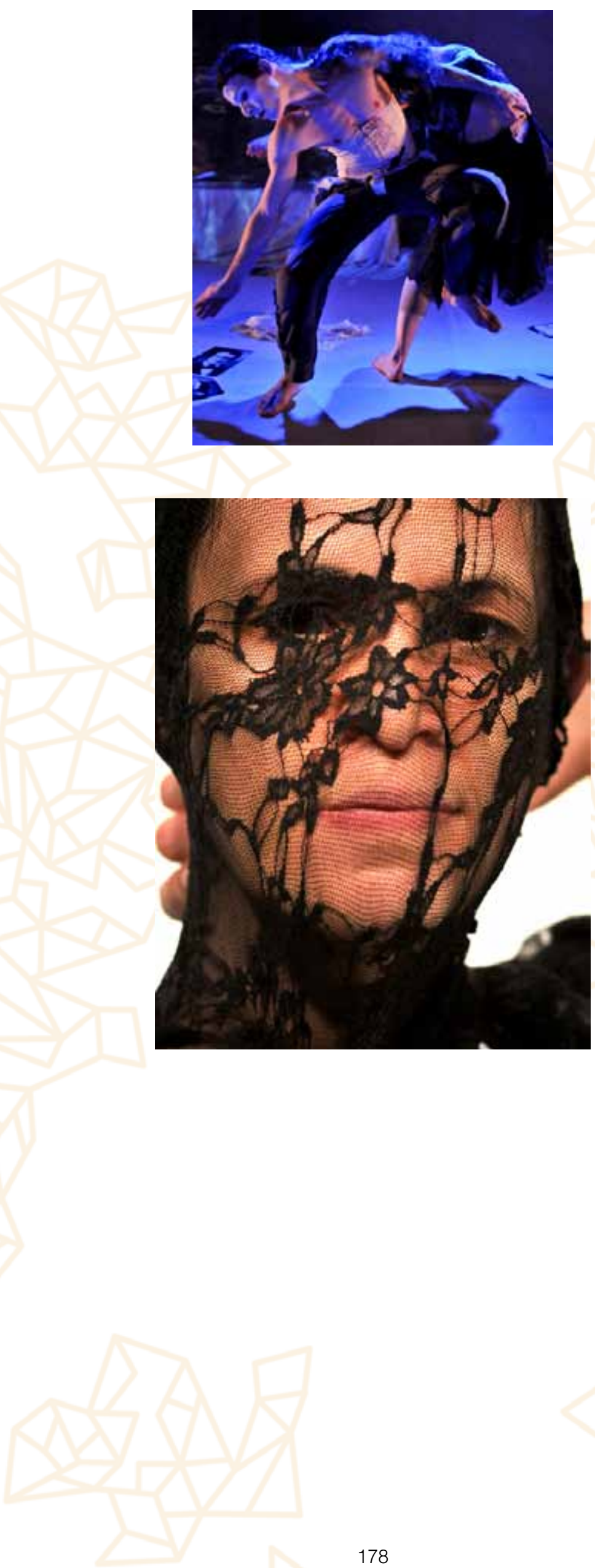

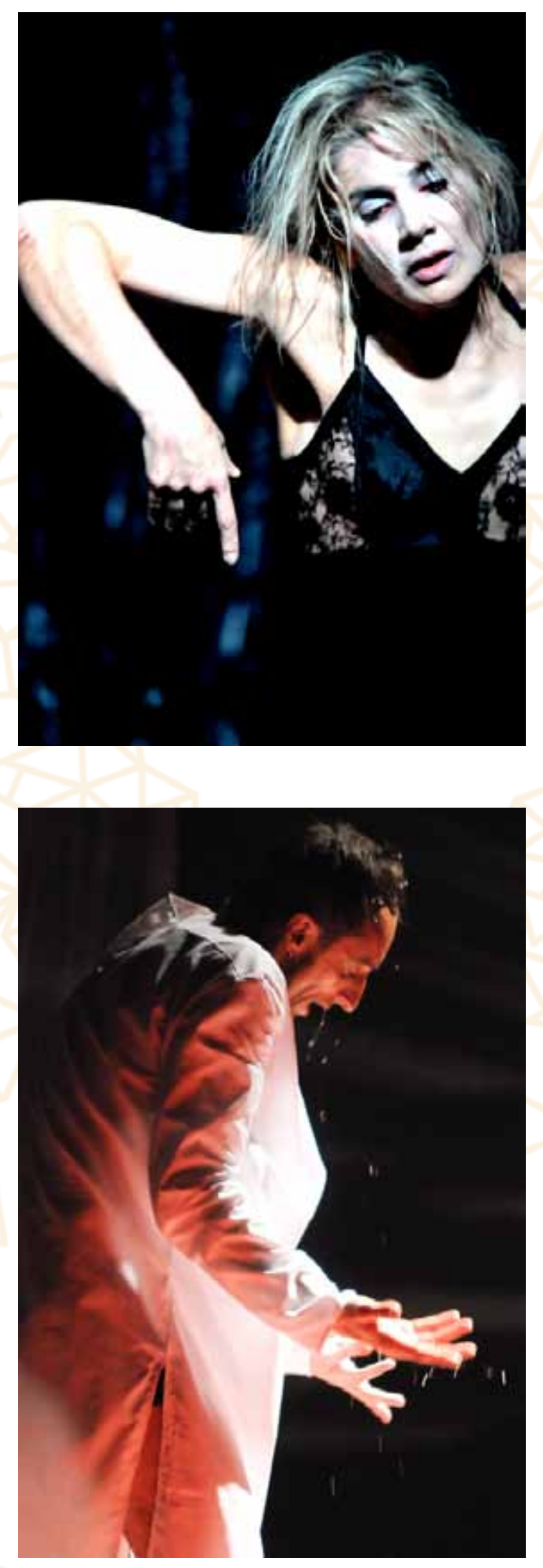

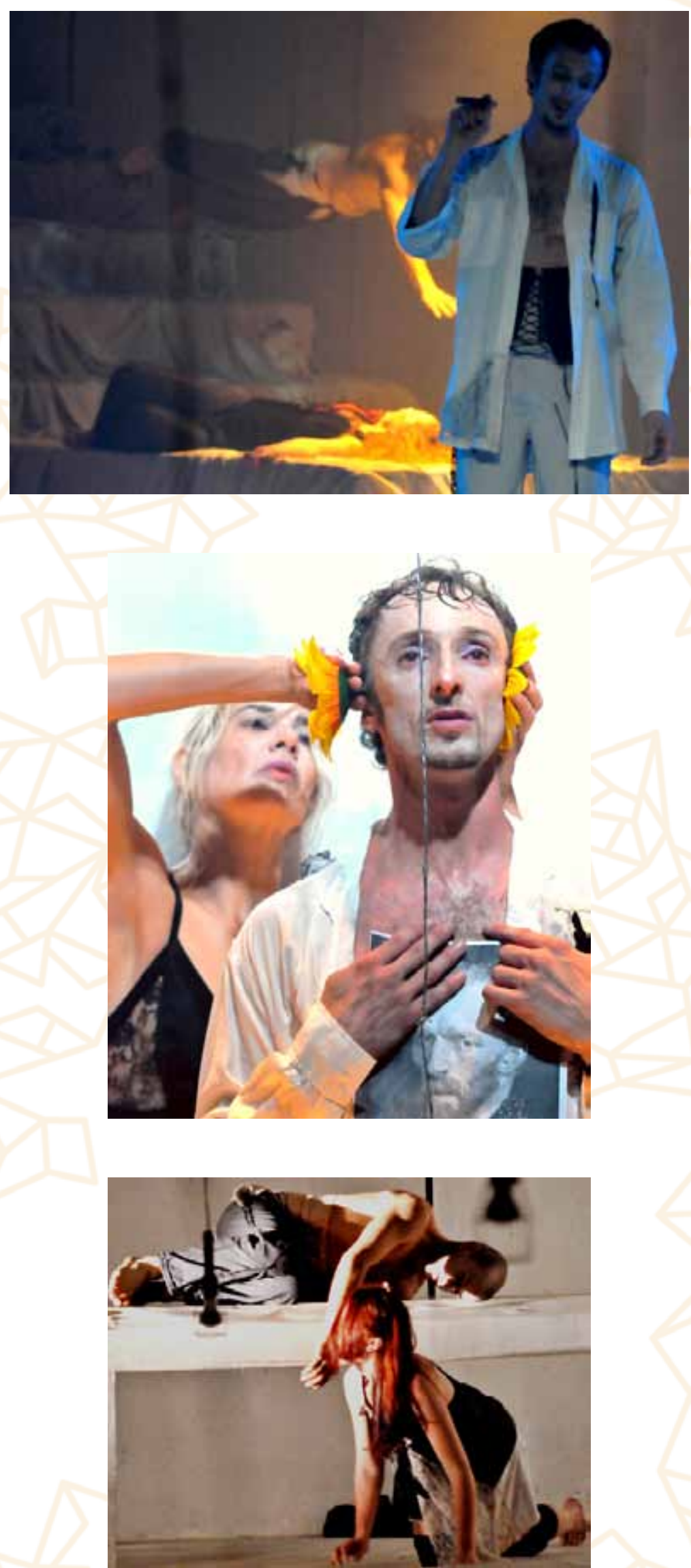

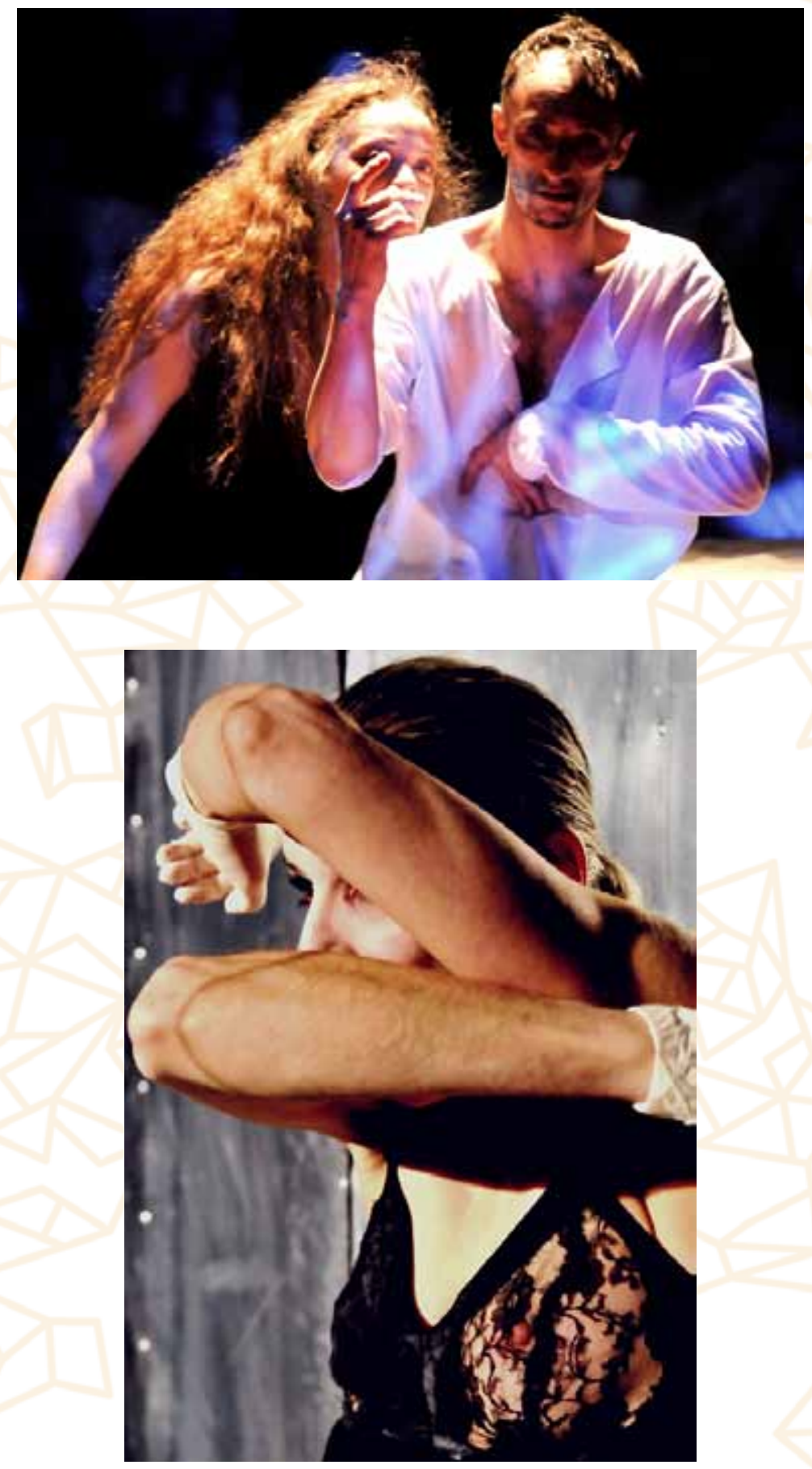

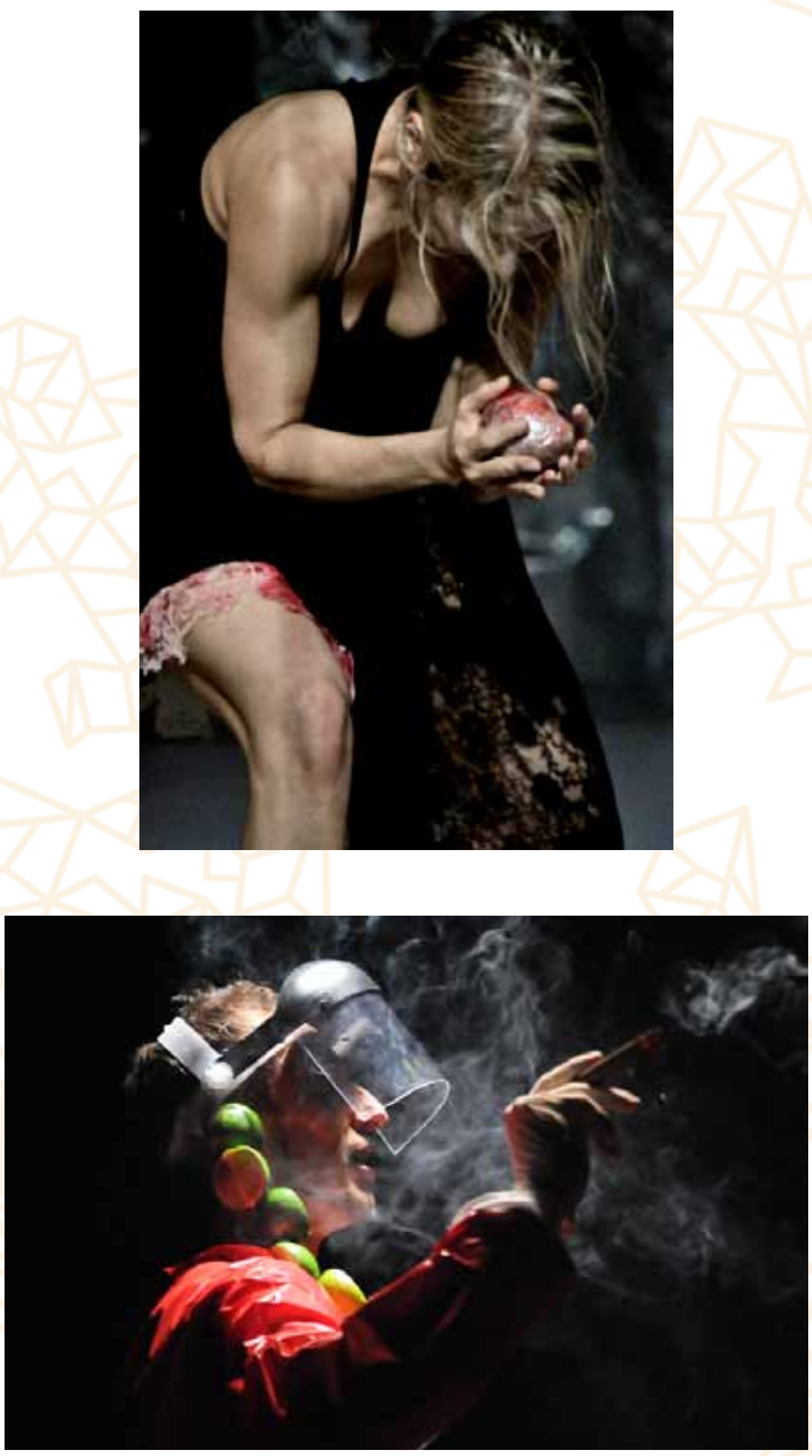